\title{
Periodontal disease as predictor of chronic liver diseases
}

\author{
Hassan Elbatae ${ }^{1}$, Ahmed Abdel-Razik ${ }^{2}$, Eman Mousa ${ }^{3 *}$, Mostafa Elshenaway ${ }^{2}$, \\ Sameh Abdel Monem ${ }^{4}$, Ahmed El Shabrawi ${ }^{2}$, Amr Samir $^{2}$, Nasser Mousa ${ }^{2}$ \\ ${ }^{1}$ Hepatology, Gastroenterology and Infectious Diseases dept., Kafr El Sheik Univ., Egypt; ${ }^{2}$ Tropical \\ Medicine dept., Mansoura Univ., Egypt; ${ }^{3}$ Faculty of Dentistry, Mansoura Univ., Egypt; \\ ${ }^{4}$ Tropical Medicine dept., Zagazig Univ., Egypt. \\ *eman.nasser.mousa@gmail.com
}

Received: $8-1-2020$

Accepted: $20-3-2020$

Abstract: Periodontal disease is a chronic infectious disease of the tissues surrounding the teeth that result in tooth loss. It affects up to $50 \%$ of the adult population worldwide. Serious periodontitis has been reported as the sixth most common infection around the world. Periodontal disease has been associated with liver disease. Moreover, dental infections may impact the clinical course of liver disease. Furthermore, untreated dental problems can lead to infections and sepsis and may cause many complications in liver transplanted patients. The results of studies documented high levels of dental management among patients with chronic liver diseases. Therefore, periodontitis in patients with chronic liver disease need to be detected early and treated under collaborative of hepatologist and dentist in order to prevent progression of chronic liver disease.

Keywords: Periodontitis, Chronic liver disease, Infection.

\section{Introduction}

Periodontitis is an inflammatory disorder of many etiologies that impacts the supporting tissues of the teeth and is characterized by deepening of periodontal pockets, connective tissue attachment loss and alveolar bone loss. Unmanaged, periodontitis can result in anxiety, impaired mastication, pain, and lastly tooth loss ${ }^{1,2}$. Studies indicated that patients suffering from cirrhosis showed a considerably larger loss of attachment, as well as having more plaque . $^{3,4}$. There is an association between periodontal disease and advancement of liver disease, as measured by the progression of the MELD score during the 12 months preceding dental examination ${ }^{5}$. In addition, there was a positive correlation between periodontal breakdown and serum alkaline phosphatase levels in liver cirrhosis patients ${ }^{6}$. Studies show that, periodontitis related systemic inflammation may additionally initiate liver injury and exacerbate both alcoholic and non-alcoholic liver disease ${ }^{\mathbf{7}, 8}$. Though, the clinical importance of these findings is uncertain. Bacteria typically involved in oral infections, such as streptococcus viridans, are more being known as etiology of SBP among cirrhotic patients, ${ }^{\mathbf{9}, 10}$. Using tooth loss as a variable agent for periodontal disease, many studies have evaluated the relationship between tooth loss and risk of liver cancer ${ }^{11-13}$. These studies reported that, there was an increased risk of liver cancer among patients with higher tooth loss ${ }^{12,13}$. On the contrary, another study demonstrated that, there was no relationship between tooth loss and liver cancer $^{11}$.

Prevalence of periodontal disease in patients with liver cirrhosis

Periodontitis is one of the major inflammatory diseases affects about half of the adult persons and has been reported as the $6^{\text {th }}$ most frequent disease global. In its severe form, it leads to damage of toothsupporting structures ${ }^{\mathbf{1 4 , 1 5}}$. There was a wide variation in occurrence of periodontitis among the studies. Some studies, reported frequency of periodontal disease ranged from $25.0 \%$ to $68.75 \%{ }^{16,17}$. Among patients with cirrhosis, the occurrence of apical periodontitis ranged from $49 \%$ to $79 \%{ }^{81,19}$. The results of a systematic review by Grønkjær found that, a large number of cirrhotic patients had a poor oral health, moreover, periodontal disease was demonstrated in 25-69\% and apical periodontitis was found in $49-79 \%$ in these groups of patients ${ }^{20}$. The predictors of severe periodontitis included smoking, brushing teeth twice daily and visiting the dentist once a year. Interestingly, both the cause and the degree of cirrhosis was not predictors of severity of periodontitis. It was found that, the patients with severe periodontitis had a greater nutritional risk score versus patients with moderate-non periodontitis ${ }^{21}$.

\section{Pathogenesis}

Periodontal and chronic liver diseases have a bidirectional harmful impact on each other. This is because of the inflammatory nature of the two diseases and the important role of the liver in clearing of bacteria from the body ${ }^{22}$. It was found that, Serum cytokine is increased in cirrhotic patient because of liver dysfunction. These might be implicated in the destructive process of the periodontal disease, possibly via stimulation of collagen and metalloproteinase activity ${ }^{23}$. On the other side, in patient with severe periodontitis, the periodontal bacteria and their toxins and locally produced cytokines were passed into the circulation resulting in increase serum 
levels of interleukin-6, tumor necrosis factor-alpha, and endotoxins, such as lipopolysaccharides augmented systemic inflammation ${ }^{24,25}$. These effects may be accentuated in liver cirrhosis which result in decreasing clearance of circulating endotoxins, bacteria and inflammatory mediators by the dysfunctional liver $^{26}$. Moreover, in cirrhotic patients, there was a marked reduction in capillaries in the periodontal and oral mucosa as compared with that in the normal liver. This is an essential factor in the reduction of the self defensive mechanism of the periodontium and consequently the progression of the periodontal disease ${ }^{27}$. Also, many research highlights the significance of depressed psychological state of the cirrhotic patients that lead to the negligence of the oral hygiene and subsequently precipitating for the periodontitis ${ }^{28,29}$. Another explanation for the association of periodontitis and chronic liver disease is an impairment of the patient's immune system in hepatic patients. This disturbance of the immune system disrupts the ecological balance of the oral cavity, push periodontal bacterial pathogens to create an inflammatory reaction. Later, the inflammation becomes chronic and causes the periodontal tissues' dissolution $^{\mathbf{3 0}}$. Malnutrition and infections are frequent problems of cirrhosis linked to increased morbidity and mortility ${ }^{31}$. Periodontitis itself may have unfavorable health effects and it has been linked with malnutrition and systemic inflammation ${ }^{32,33}$. So periodontitis may aggravate the liver condition.

\section{Oral manifestations in the cirrhotic patient cholestatic liver diseases}

Cholestasis results from decrease (intra or extrahepatic) excretion of biliary components to the small intestine. Newborns, especially preterm-born children, have a predisposition to neonatal cholestasis due to hepatic immaturity ${ }^{34}$. Cholestasis can modify the structural composition or thickness of the mineralized dental tissues, enamel and dentine, also leading to intrinsic chromatic changes due to hyperbilirubinemia $^{35}$. Chronic elevated bilirubin results in its deposition into the enamel and/or dentine during the period of matrix mineralization, consequently changes its coloration permanently ${ }^{36,37}$. Moreover, some author suggested that, tooth can be use as noninvasive marker for progression of bilirubinemia in cholestatic liver disease ${ }^{38}$.

\section{Oral diseases related to hepatitis $C$ virus infection}

Several studies address the impact of HCV infection in the oral health. These studies highlight the dental diseases associated with both HCV-infection and its extrahepatic manifestations (EHMs) ${ }^{39}$. Coates et al, studied the oral health state of HCVinfected persons based on the DMFT index (Decayed, Missing, Filled Teeth index). They found that, patients with chronic HCV infection had more significant dental pathological changes in teeth with carious lesions, expressed a larger number of missing teeth and less dental fillings as compared with the control $^{40}$. Moreover, using the CPITN index (Community Periodontal Index of Treatment Needs), HCV patients had more gingival bleeding and deeper periodontal pockets. Furthermore, a tendency for impaired periodontal status has been noted in infected patients. The authors concluded that, diet characteristics and different social particularities like shortness of correct dental and periodontal management could be the reason for this trend ${ }^{\mathbf{4 0}}$. Insulin resistance (IR) and chronic inflammation may explain the influence of chronic hepatitis $\mathrm{C}$ on periodontal status. Chronic $\mathrm{HCV}$-infection characterized by insulin resistance (IR) and chronic inflammatory state. This condition associated with creation of many cytokines such as (mainly TNF-alpha, adiponectin, and IL-6). These cytokines are involved either in (periodontal disease, triggering and progression) or in the connection between periodontal disease and $\mathrm{IR}^{\mathbf{4 1 , 4 2}}$. Also, studies have shown that, there is an increased incidence of dry mouth in patients with HCV infection. Lack of salivary secretion may result in many problems such as, dental caries, burning sensation in the mouth, candidiasis, trouble chewing, difficulty wearing dentures ${ }^{43}$. Lichen planus (LP) is a chronic mucocutaneous disease; however, this varies by region genotypes of HCV. Oral lichen planus (OLP) is often bilateral and typically presents as a mixture of clinical subtypes that characteristically bear fine white striations known as Wickham's striae. The studies found that, there is an association between LP and $\mathrm{HCV}$ proved by the presence of anti-HCV antibodies and HCV RNA in the blood of these patients ${ }^{4-46}$. It is recognized that $\mathrm{HCV}$ affects the salivary glands with un-clear mechanism. Hepatitis $\mathrm{C}$ virus is believed to cause a syndrome with features like Sjogren's Sydnrome (a chronic autoimmune disease which affects the secretory glands of the body as lachrymal and salivary glands) in a proportion of infected individuals. Moreover, some authors suggested that, HCV may lead to the development of $\mathrm{SS}^{47}$. The Sjogren's Sydnrome (SS) is associated with marked reduction in saliva flow into the oral cavity leading to, dryness of oral cavity and subsequently, the teeth no longer protected against bacteria by salivary components and the dental plaque are no longer removed by the saliva flow. This dryness of mouth leading to dental caries and fragile oral mucosa which becomes more susceptible to trauma and infection ${ }^{41}$. The direct infection and proliferation of $\mathrm{HCV}$ in salivary glands together with formation of immune complexes containing HCV may explain the association between the SS and $\mathrm{HCV}$ infection ${ }^{48,49}$.

\section{Oral diseases associated with hepatitis $B$ virus}

\section{Infection}

The role of oral fluid on the periodontal condition of patients with viral hepatitis is debatable. However, $\mathrm{HBV}$ and HCV markers in gingival crevicular fluid 
(GCF) have been studied. GCF, a serum transudate or inflammatory exudate, can be collected from gingival crevice surrounding the teeth. GCF contains microbial plaque, host inflammatory cells, host tissue and serum-derivers factors ${ }^{\mathbf{5 0}}$. Hepatitis B surface antigen (HBsAg) was found in GCF and whole saliva in approximately $90 \%$ of $\mathrm{HBV}$-infected persons. These data support the idea that, GCF may be a significant source of hepatitis virus in saliva ${ }^{\mathbf{5 1}}$. Persson et al. demonstrated that, AST levels can be used to assess the presence and extent of periodontal inflam-mation and GCF is probable the source of HBsAg in saliva ${ }^{52}$. Moreover, periodontitis might be a pre-dictor of progression of viral liver disease; hence, early detection of oral disease is essential for the prevention and management of liver fibrosis ${ }^{\mathbf{5 3}}$. Cringuta Paraschiv et al, found that there was a strong association between chronic $\mathrm{HBV}, \mathrm{HCV}$ and periodontal disease, gingival bleeding and dry mouth $^{54}$

\section{Oral diseases associated with NAFLD}

NAFLD is the commonest form of chronic liver disease nowaday ${ }^{55}$. In the Japanese college study, a significant periodontitis was found in male patients and females aged (20-59) years with a high level of serum ALT in comparison to those with a low level of serum $\mathrm{ALT}^{56}$. Moreover, studies demonstrated that, in patients with periodontal pockets (depth, $\geq 4 \mathrm{~mm}$ ), ALT and GGT levels were higher when compared to healthy controls ${ }^{57}$. Interestingly, periodontal management of these patients improved serum aspartate transaminase and ALT in NAFLD patients ${ }^{58}$. Such periodontal treatments consist of, oral hygiene measures; including scaling, root planning procedures and application of minocycline hydrochloride. Recently, studies indicating the frequent presence of porphyromonas gingivalis in patients with non-alcoholic fatty liver disease suggested a close association between periodontitis and NAFLD/ $\mathrm{NASH}^{\mathbf{5 9 , 6 0}}$. In addition, evidence from an epidemiological survey and a clinical study show that NAFLD is associated with periodontitis and that, the association is stronger with significant liver fibrosis ${ }^{\mathbf{6 0}}$.

\section{Conclusion}

Periodontitis is a missed problem in patients with chronic liver diseases. This problem requires early detection of periodontitis by dentists and also, the cooperation between dentists and herpetologist in order to prevent chronic liver disease progression.

\section{References \\ [1] Raghava K, Shivananda H, Mundinamane} D. Evaluation of periodontal status in alcoholic liver cirrhosis patients: A comparative study. J. Contemp Dent Pract. 2013; 14: 179-182 .

[2] Movin S. Relationship between periodontal disease and cirrhosis of the liver in humans. J. Clin Periodontol. 1981; 4: 450-458 .

[3] Åberg F, Helenius-Hietala J, Meurman J. Association between dental infections and the clinical course of chronic liver disease. Hepatol Res. 2014; 44: 349-353

[4] Lins L, Bittencourt P, Evangelista M, Lins R, Codes L, Cavalcanti A. et al. Oral health profile of cirrhotic patients awaiting liver transplantation in the Brazilian Northeast. Transplant Proc. 2011; 43: 1319-1321.

[5] Pihlstrom B, Michalowicz B, Johnson N. Periodontal diseases. Lancet. 2005; 366:1809-20

[6] Listgarten M. Pathogenesis of periodontitis. J. Clin Periodontol. 1986; 13: 418-430.

[7] Tomofuji T, Sanbe T, Ekuni D, Azuma T, Irie $\mathrm{K}$, Maruyama T, et al. Oxidative damage of rat liver induced by ligature-induced periodontitis and chronic ethanol consumption. Arch Oral Biol. 2008; 53: 1113-1118 .

[8] Hyvärinen K, Tuomainen A, Laitinen S, Bykov I, Törmäkangas L et al. Chlamydial and periodontal pathogens induce hepatic inflammation and fatty acid imbalance in apolipoprotein E-deficient mice. Infect Immun. 2009; 77: 3442-3449 .

[9] Bert F, Noussair L, Lambert-Zechovsky N, Valla D. Viridans group streptococci: An under estimated cause of spontaneous bacterial peritonitis in cirrhotic patients with ascites. Eur J. Gastroenterol Hepatol. 2005; 17: 929-933 .

[10] Cholongitas E, Papatheodoridis G, Lahanas A, Xanthaki A, Kontou-Kastellanou C, Archimandritis A. Increasing frequency of Gram-positive bacteria in spontaneous bacterial peritonitis. Liver Int. 2005; 25: 57-61.

[11] Ansai T, Takata Y, Yoshida A, Soh I, Awano $\mathrm{S}$, Hamasaki $\mathrm{T}$, et al. Association between tooth loss and orodigestive cancer mortality in an 80-year-old community-dwelling Japanese population: a 12-year prospective study. BMC Public Health. 2013; 13: 814 .

[12] Hiraki A, Matsuo K, Suzuki T, Kawase T, Tajima K. Teeth loss and risk of cancer at 14 common sites in Japanese. Cancer Epidemiology, Biomarkers \& Prevention. 2008; 17 (5): 1222-1227 .

[13] Yang B, Petrick J, Abnet C, Graubard B, Murphy G, Weinstein S, et al. Tooth loss and liver cancer incidence in a Finnish cohort. Cancer Causes \& Control. 2017; 28 (8), 899-904.

[14] Eke P, Thornton-Evans G, Wei L, Borgnakke W, Dye B. Accuracy of NHANES periodontal examination protocols. J. Dent Res. 2010; 89: 1208-1213.

[15] Tonetti M, Chapple I, Jepsen S, Sanz M. Primary and secondary prevention of perio- 
dontal and peri-implant diseases: Introduction to, and objectives of the $11^{\text {th }}$ European Workshop on Periodontology consensus conference. J Clin Periodontol. 201542 (Suppl 16): S1-S4

[16] Silva Santos P, Fernandes K, Gallottini MHC. Assessment and management of oral health in liver transplant candidates. J. Appl Oral Sci. 2012; 20: 241-245.

[17] Guggenheimer J, Eghtesad B, Close J, Shay C, Fung J. Dental health status of liver transplant candidates. Liver Transpl. 2007; 13: 280-286.

[18] Castellanos-Cosano L, Machuca-Portillo G, Segura-Sampedro J, Torres-Lagares D, LópezLópez J, Velasco-Ortega E et al. Prevalence of apical periodontitis and frequency of root canal trea-tments in liver transplant candidates. Med Oral Patol Oral Cir Bucal. 2013; 18: 773-779.

[19] Lins L, Bittencourt P, Evangelista M, Lins R, Codes L, Cavalcanti A, et al. Oral health profile of cirrhotic patients awaiting liver transplantation in the Brazilian northeast. Transplant Proc. 2011; 43 (4): 1319-1321.

[20] Gronkjaer L. Periodontal disease and liver cirrhosis: A systematic review. SAGE Open Med. 2015; 3: 1-11.

[21] Grønkjær L, Holmstrup P, Schou S, Kongstad J, Jepsen P, Vilstrup H. Periodontitis in patients with cirrhosis: A cross-sectional study. BMC Oral Health. 2018; 18 (1), 22 doi: 10.1186/s1 2903-018-0487-5

[22] Elhassan A, Peeran S. The Linking mechanisms between liver and periodontal diseases. EC Dental Science. 2016; 4 (2): 758-766.

[23] Raghava K., Shivananda H, Mundinamane D, Boloor V, Thomas B. Evaluation of periodontal status in alcoholic liver cirrhosis patients: A comparative study. J. of Contemporary Dental Practice. 2013; 14 (2): 179-182.

[24] Offenbacher S, Barros S, Beck J. Rethinking periodontal inflammation. J. Periodontol. 2008; 79 (Suppl 8): 1577-1584.

[25] Kallio K, Buhlin K, Jauhiainen M, Keva R, Tuomainen A, Klinge B, et al. Lipo-polysaccharide associates with pro-atherogenic lipoproteins in periodontitis patients. Innate Immun 2008; 14: 247-253 .

[26] Ashare A, Stanford C, Hancock P, Stark D, tark D, Lilli K, Birrer E, et al. Chronic liver disease impairs bacterial clearance in a human model of induced bacteremia. Clin Transl Sci 2009; 2: 199-205.

[27] Funatsu K, Yamada M, Kawishima Y, Nishida J, Ueno M, Ebihara Y, Mizuno Y, Oda M, Tsuchiya M. Microcirculatory disturbances of oral mucosa and periodontal disease in patients with liver cirrhosis. J. of Gastroent- erology and Hepatology. 1989; 4 (Suppl 1): 99-102.

[28] Anand A, Pardal P, Sachdev V. Dental caries and periodontal disorders in chronic liver disease. Medical J. Armed Forces India. 200157 (1): 26-30.

[29] Lins L, Bittencourt P, Evangelista M, Lins R, Codes L, Cavalcanti A, et al. Oral health profile of cirrhotic patients awaiting liver transplantation in the Brazilian Northeast. Transplantation Proc. 2011; 43 (4): 1319-1321.

[30] Silva N, Abusleme L, Bravo D, Dutzan N, Garcia-Sesnich J, Vernal R, et al. Host response mechanisms in periodontal diseases. J. of Applied Oral Science. 2015; 23 (3): 329-355.

[31] Johnson T, Overgard E, Cohen A, DiBaise J, et al. Nutrition assessment and management in advanced liver disease. Nutr Clin Pract. 2013; 28: 15-29.

[32] Chen L, Chiang C, Chan C, Hung K, Huang C, et al. Does periodontitis reflect inflammation and malnutrition status in hemodialysis patients? Am J. Kidney Dis. 2006; 47: 815822.

[33] Belstrøm D, Damgaard C, Nielsen C, Holmstrup $\mathrm{P}$, et al. Does a causal relation between cardiovascular disease and periodontitis exist?. Microbes Infect. 2012; 14: 411-418.

[34] Feldman A, Sokol R. Neonatal cholestasis. Neoreviews. $2013 ; 14$ (2): 1-21 .

[35] Roquete M. Colestase neonatal J. de Pediatria. 2000; 76 (2): pp. S187-SS97

[36] Guimarães L, Silva T. Green teeth associated with cholestasis caused by sepsis: A case report and review of the literature. Oral Surg Oral Med Oral Pathol Oral Radiol Endod. 2003; 95 (4): 446-451.

[37] Bimstein E, Magliocca K, Cohen D, Morelli G, Katz J. Hyperbilirubinemic stain: Location and extent in dental tissues. J. Clin Pediatr Dent. 2011; 36 (1): 75-78.

[38] Rogelio V, Bruzadin L, Toma R, Bizeto M, Mugayar L, Jun Koh IH. Oral Surg Oral Med Oral Pathol Oral Radiol. 2017; 123 (2): 188193.

[39] Alavian S, Mahboobi N. Mahboobi N, and Karayiannis P. Oral conditions associated with hepatitis C virus infection. The Saudi J. of Gastroenterology. 2013; 19 (6): 245-251.

[40] Coates E, Brennan D, Logan R, Goss A, Scopacasa B, Spencer A, et al., Hepatitis C infection and associated oral health problems. Australian Dental J. 2000; 45 (2): 108-114.

[41] Gheorghe D, Foia L, Toma V, Surdu A, Herascu E, Popescu D, et al. Hepatitis C infection and periodontal disease: Is there a Common Immunological Link?. J. Immunol Res. 2018; 2018: doi: 10.1155/2018/8720101. 
[42] Martinez-Herrera M, Silvestre-Rangil J, Silvestre F. Association between obesity and periodontal disease. A systematic review of epidemiological studies and controlled clinical trials. Medicina Oral, Patología Oral y Cirugía Bucal. 2017; 22 (6): 708-715.

[43] Farghaly A, Mansour G, Mahdy N, Yousri A. Hepatitis $\mathrm{B}$ and $\mathrm{C}$ virus infections among patients with gingivitis and adult periodontitis: Seroprevalence and public health importance. J. Egypt Public Health Assoc. 1998; 73 (56): 707-735.

[44] Carrozzo, M., Oral diseases associated with hepatitis $\mathrm{C}$ virus infection - Part 2: Lichen planus and other diseases. Oral Dis. 2008; 14 (3): 217-228.

[45] Australasian Society for HIV Medicine, Dental and orofacial health and hepatitis C. ASHM, 2012.

[46] Lodi, G, Giuliani M, Majorana A, Sardella A, Bez C, Demarosi F, et al. Lichen planus and hepatitis $C$ virus: A multicentre study of patients with oral lesions and a syste-matic review. $\mathbf{B r}$ J. Dermatol. 2004; 151 (6): 1172-1181.

[47] Carrozzo M. Oral diseases associated with hepatitis C virus infection - Part 1: Sialadenitis and salivary glands lymphoma. Oral Dis. 2008; 14 (2):123-130.

[48] Jadali Z, Alavian S. Autoimmune diseases co-existing with hepatitis $\mathrm{C}$ virus infection. Iran J Allergy Asthma Immunol. 2010; 9: 191-206.

[49] Ramos-Casals M, Garcia-Carrasco M, Cervera $\mathrm{R}$, Font J. Is hepatitis $\mathrm{C}$ virus a sialotropic virus?. Am J. Pathol. 2001; 159: 1593-1594.

[50] Embery G, Waddington R. Gingival crevicular fluid: Biomarkers of periodontal tissue activity. Adv Dent Res. 1994; 8 (2): 329-336 .

[51] Persson G, DeRouen T, Page R. Relationship between gingival crevicular fluid levels of aspartate aminotransferase and active tissue destruction in treated chronic periodontitis patients. J. Periodontal Res. 1990; 25 (2): 81-87.
[52] Ben-Aryeh H, Ur I, Ben-Porath E. The relationship between antigenaemia and excretion of hepatitis B surface antigen in human whole saliva and in gingival crevicular fluid. Arch Oral Biol. 1985; 30 (1): 97-99.

[53] Nagao Y, Kawahigashi Y, Sata M. Association of periodontal diseases and liver fibrosis in patients with $\mathrm{HCV}$ and/or HBV infection. Hepat Mon. 2014; 14 doi: 10.5812/hepatmon.23264

[54] Paraschiv C, Gavrilescu C, Cotea I, Esanu I, Ghiuru R, Munteanu D. Oral manifestations in liver diseases. Romanian J. of Oral Rehab. 2011; 3 (1): 24-29

[55] Angulo P. Nonalcoholic fatty liver disease. $\mathbf{N}$ Engl J Med. 2002; 346: 1221-1231.

[56] Furuta M, Ekuni D, Yamamoto T, Irie K, Koyama R, Sanbe T, et al. Relationship between periodontitis and hepatic abnormalities in young adults. Acta Odontol Scand. 2010; 68: 27-33.

[57] Morita T, Yamazaki Y, Fujiharu C, Ishii T, Seto M, Nishinoue N, et al. Serum $\gamma$-glutamyl transferase level is associated with periodontal disease independent of drinking habits in Japanese adults. Med Sci Monit. 2014; 20: 21092116.

[58] Yoneda M, Naka S, Nakano K, Wada K, Endo H, Mawatari H, et al. Involvement of a periodontal pathogen, Porphyromonas gingivalis on the pathogenesis of non-alcoholic fatty liver disease. BMC Gastro-enterol. 2012; 12: 16 doi: 10.1186/1471-230X-12-16.

[59] Han P, Sun D, Yang J. Interaction between periodontitis and liver diseases. Biomed Rep. 2016; 5: 267-76.

[60] Alazawi W, Bernabe E, Tai D, Janicki T, Kemos P, Samsuddin S, et al. Periodontitis is associated with significant hepatic fibrosis in patients with non-alcoholic fatty liver disease. PLoS One. 2017; 12 doi: 10.1371/journal.pone. 0185902 